\title{
One in three adolescent schoolgirls in urban northwest Ethiopia is stunted
}

\author{
Samuel Mersha Birru', Aysheshim Kassahun Belew ${ }^{2^{*}}$ and Amare Tariku
}

\begin{abstract}
Background: Poor nutritional status of adolescent girls has a negative effect on the next generation as undernourished adolescents enter pregnancy with poor nutrient reserve. However, there is scarcity of evidence showing the burden of stunting among adolescent girls in Ethiopia. Therefore, the objective of this study aimed to assess prevalence of stunting and associated factors among school adolescent girls in Gondar City Administration, northwest Ethiopia.

Methods: Cross-sectional study was conducted from March to April, 2017. A multi-stage sampling technique was used to select812 school adolescent girls. World Health Organization Anthro-plus software was used to analyze anthropometric data into Height for Age Z-score. A multivariable logistic regression analysis was employed to identify the factors associated with stunting. Adjusted Odds Ratio (AOR) with 95\% confidence interval was used to show the strength of association, while a $P$-value $<0.05$ of was used to declare the significance of association.

Results: The overall prevalence of stunting among adolescent girls was 33.1\% (95\% Cl: 29.9, 36.5). Middle age of adolescence (AOR $=0.22,95 \% \mathrm{Cl}: 0.15,0.34)$, unsatisfactory media exposure $(\mathrm{AOR}=1.69,95 \% \mathrm{Cl}: 1.01,2.84)$ and poor mother's education ( $\mathrm{AOR}=2.84,95 \% \mathrm{Cl}: 1.07,7.94)$ were significantly associated with stunting.

Conclusions: One-third of adolescent girls are stunted in Gondar City which suggests the serious public health importance of the problem. Enhancing mother's education and media exposure are critical to address the high burden of stunting.
\end{abstract}

Keywords: Stunting, Adolescent girls, Media exposure, Urban settlement, Ethiopia

\section{Background}

Globally, adolescents comprise 16\% (1.2 billion) of world population, more than $40 \%$ of which are adolescent girls. Of the total adolescent girls, 16 million give birth every year, off this $23 \%$ are from the sub-Saharan Africa, the region where the highest burden of maternal and child under nutrition is frequently reported [1]. Nutrition, optimal energy and micronutrient intake, plays an important role in supporting physical, mental and emotional development of adolescents [2, 3].

Poor nutritional status of adolescent girls, including stunting, has a negative effect on generation. Hence, undernourished adolescents enter pregnancy with poor nutrient reserve. Consequently they will give birth to low birth weight baby that is more vulnerable to chronic disease in later life due to early fetal programming $[4,5]$. Moreover, it

\footnotetext{
* Correspondence: aysheshim121@gmail.com

${ }^{2}$ Department of Human Nutrition, Institute of Public Health, University of

Gondar, Gondar, Ethiopia

Full list of author information is available at the end of the article
}

is associated with high risk of morbidity and mortality, delayed mental development, reduced intellectual capacity, poor educational achievement, school attendance and concentration $[6,7]$. As a result, under nutrition is considered as a strong predictor of human capital and social progress [8]. However, not trivial numbers of adolescents are undernourished in developing countries [8-10]. The high prevalence of adolescent stunting is reported in Asia and Africa. As an illustration, nearly half of (47.0-47.4\%) adolescent girls are stunted in India [11, 12] and Bangladesh (32-49\%) $[13,14]$. On the other hand, about 12.1 and $17.4 \%$ of adolescents have stunted growth in Kenya [15] and Nigeria [16], respectively, which is lower than Asian countries report. As like other developing countries, adolescent stunting existed as public health problem in Ethiopia [17]. Onethird (31.5\%) of adolescent girls are affected by stunting in Amhara region, the region where the study area is located [18]. Similarly, higher prevalence (25.5\%) of stunting is shown in Eastern Tigray [19]. Nevertheless, a bit lower 
burden of adolescent stunting is reported in City Administration of the country: $15.6 \%$ in Adama [18] and 12.2\% from Adawa city [19].

Some of the former literatures identified the determinants of adolescent stunting. Attending public schools, low maternal education [16], not starting menarche [20], being in the middle age range [21], rural residence [21], use of unimproved water sources [19] and larger family size [19] were elicited as significant predictors of stunting.

Even though adolescence is identified as a part of critical window to address different nutritional problems [8], adolescent nutrition receives less attention as compared to child and maternal nutrition issues [22]. Recently the government of Ethiopia starts to pay especial emphasis to enhance adolescent's nutritional status: the revised National Nutrition Program (NNP) and national school health and feeding programs are some of the current efforts which has been implemented in the country at large $[17,23]$. The NNP baseline survey report showed that $23 \%$ of adolescent girls are stunted in Ethiopia [24] which implies the critical importance of regular monitoring and evaluation of the magnitude of stunting. Also, the observed discrepancy in the burden of adolescent stunting between urban and rural settlements $[18,19,25,26]$, necessitates further, separate, investigation of the specific determinants of stunting, though only few literature is available on the specific area. Therefore, this research intended to assess prevalence and associated factors of stunting among school adolescent girls in Gondar City Administration, northwest Ethiopia.

\section{Methods}

\section{Study setting and design}

A school based cross-sectional study was conducted from March to April, 2017 in Gondar City Administration, northwest Ethiopia. Gondar City is a capital of North Gondar Zone, one of the densely populated Zone in Amhara National Regional State. The city has 11 rural kebeles (the smallest administration unit in Ethiopia) and 12 sub-cities. Based on the Central Statistics Agency population projection in 2014, a total of 306,246 people lives in the City [27]. In the City, 30 primary and 9 secondary and preparatory schools are owed by the government, while 12 primary and 5 secondary and preparatory are registered as private schools. At the moment, a total of 38,960 students in both public and private schools were found attending their education, of which 20,475 were female adolescent girls.

\section{Sample size and sampling procedure}

All adolescent girls (10-19 years of age) attending governmental and private schools in Gondar City Administration were the source population for this study. The sample size was calculated using a single proportion formula by considering the following assumptions; $12.2 \%$ as previous prevalence of stunting among adolescent girls in Adwa Town in Tigray Region, North Ethiopia [19], the determination of sample size(n) for this study was calculated by the following formula.

$$
\mathrm{n}=\mathrm{z}^{2} \mathrm{p}(1-\mathrm{p}) / \mathrm{d}^{2}
$$

Where, $\mathrm{Z}$ is critical value for normal distribution at 95\% confidence level of two tailed which is equal to $1.96, \mathrm{P}$ is the previous prevalence of stunting among adolescent girls was $12.2 \%$, and $\mathrm{d}$ is degree of precision it was $3 \%$. Then, multiply by the design effect of 1.5 . With this assumption the sample size $(\mathrm{n})$ was $=(1.96)$ $0.122(1-0.122) /(0.03) \times 1.5=753$. Then, 75 of respondents were obtained by adding $10 \%$ of non-response of the respondents. Finally, sample size computed was 812 .

A multistage stratified sampling followed by systematic sampling technique was employed to select study participants. Primarily, secondary and preparatory schools were stratified into government and private. Then, eight governmental and three private schools were selected by lottery method. Sampling frame was prepared by taking a complete list of students enrolled in the selected schools. Quantity of students included in each school was proportional to the total eligible students. Following estimation of sampling fraction $(\mathrm{k})$, samples were selected using systematic sampling technique.

\section{Data collection tool and procedures}

Structured self-administered questionnaire was used to collect data. The questionnaire was first developed in English and translated into Amharic then back translated into English by an English language and public health expert to check the consistency. Pretest was done on $5 \%$ of the sample out of the study area. Data collectors and supervisors were trained for 2 days about methods of interview and anthropometric measurements. A total of four clinical nurses as data collector and two public health experts as supervisor were recruited for the study. During the data collection, close supervision was done by the principal investigator and supervisors.

\section{Variable measurements}

Height was measured to the nearest $0.1 \mathrm{~cm}$ using height measuring stadiometer in standing position with a sliding headpiece. The subject stood up on the basal part of the device with feet together. The shoulders, buttocks, calf and heels touched the vertical stand of the stadiometer. The adolescent girls stand with their eyes in the Frankfort horizontal plane. Considering the standardized criteria, stunting is defined as height -for- age (HAZ) value of less than two standard deviations from the WHO Growth 
reference standard (2007). Consequently, adolescents with HAZ of $<-2$ were categorized as stunted, whereas those with HAZ of $\geq-2$ were considered as not stunted. On the other hand, adolescent those body mass index-for- age (BMI for age) $<-2 \mathrm{Z}$ score were classified as wasted [28].

Dietary diversity of adolescents was measured using a standardized and validated tool containing 10 food groups. Using the participants verbal report, food items eaten by adolescents was categorized under respective food groups. Then if a girl ate five or more food groups, she was considered as having adequate dietary diversity, while those who consumed less than five food groups were deemed to have inadequate dietary diversity [29].

Concerning media exposure an adolescent who read a newspaper or magazine or listen to radio, or watched television at least once per week were considered as having satisfactory media exposure. Food security was assessed using 6-items and the sum of affirmative responses to the six questions was taken. The food security status of households labeled as 0 and 1 was described as food secure and food insecure, respectively [30].

The household wealth index was determined using Principal Component Analysis (PCA) by considering the household assets, such as quantity of cereal products, house, livestock and agricultural land ownership. First, variables were coded between 0 and 1 . Then, the variables entered and analyzed using PCA, and those variables having a communality value of greater than 0.5 were used to produce factor scores. Finally, the factor scores were summed and ranked into first, second, third and fourth quartile.

\section{Data processing and analysis}

All returned questionnaire were checked for completeness and consistency of responses manually. Then, the collected data were entered into EPI-INFO version 3.5.3 and exported to SPSS version 20 for further analysis. Also, WHO Anthro- plus software was used to generate HAZ and BMI for age there by to ascertain stunting and wasting of adolescents. Descriptive statistics, such as figures, tables and frequencies, were used to summarize variables. Both bivariable and multivariable binary logistic regression analyses were used to identify factors associated with stunting. Variables with $p$-value less than 0.2 in the bivariable analysis were fitted into the multivariable logistic regression analysis. Both Crude Odds Ratio (COR) and Adjusted Odds Ratio (AOR) with the corresponding 95\% Confidence Interval were calculated to show the strength of association. Finally, in the multivariable analysis, variables with a $P$-value of less than 0.05 were considered as statistically significant.

\section{Results}

A total of 812 adolescent girls were included in the study with a response rate of $97.5 \%$. The median age of the adolescents was 16 with (Inter-Quartile Range (IQR) of 14-17 years. Substantial proportion, 742 (93.3\%) of participants resided in urban kebeles. More than half of the mothers had informal education $437(55 \%)$. Nearly half, $365(45.9 \%)$ of households had five and above family size and $168(21.1 \%)$ were found in the rich wealth category (Table 1 ).

Of the total respondents, 631(79.4\%) had satisfactory media exposure. Large proportion 776(97.6\%) of participants consumed grains and roots and $600(75.5 \%)$ of had adequate dietary diversity. Two-third $499(62.8 \%)$ of the households were food secured (Table 2). Availability of home gardening was reported in $131(16.5 \%)$ of the households, but $52.7 \%$ of which used the product for sale. Majority, 620(79.1\%) also had home latrine and used improved drinking water 783(98.5\%) (Table 3).

The study noted that the overall prevalence of stunting $(\mathrm{HAZ}<-2)$ was $33.1 \%$ and about $2.4 \%$ of adolescent girls were wasted. The multivariable logistic regression analysis showed that age of the respondent, unsatisfactory media exposure and educational status of mothers were significantly associated with stunting (Fig. 1).

Adolescent girls found in the early and middle age range were found at $74 \%(\mathrm{AOR}=0.26,95 \% \mathrm{CI}: 0.00,0.22)$ and $78 \%(\mathrm{AOR}=0.22,95 \% \mathrm{CI}: 0.15,0.34)$ lesser odds of stunting compared to late adolescent girls. The odds of stunting were higher among adolescents who had unsatisfactory media exposure $(\mathrm{AOR}=1.69,95 \% \mathrm{CI}: 1.01,2.84)$ and whose mothers completed college and above education $(\mathrm{AOR}=2.84,95 \% \mathrm{CI}: 1.02,7.94)($ Table 4$)$.

\section{Discussion}

This study illustrated that one of the three $33.1 \%(95 \%$ CI $(29.9,36.5))$ adolescent girls were stunted, suggesting the issue as one of the major public health problem. The finding is consistent with the previous report in Nepal $32 \%$ [31]. However, the report is lower than the former Asian and African countries investigations, for instance.

51.9\% of adolescent girls in Assum, India [11] and $47 \%$ in panangal [12], districts of India, are stunted. Similarly, the high magnitude of adolescent stunting is noted in Bangladesh 49\% [14] and Nigeria 57.8\%. The high prevalence of stunting in India [11] could be attributed to the nature of the study setting where only adolescents from the slum areas were included, while our study considered random selection of samples with regard to place of residence. Obviously, slum areas are well-known with insanitary living environments and lower socio-economic status, underlying causes of under nutrition, compared to non-slum settlements [32]. On the other hand, half participants in Bangladesh were pregnant compared to $95.6 \%$ of samples had no history of pregnancy in the current study. This could explain the increased magnitude of stunting Bangladesh. 
Table 1 Socio-demographic characteristics of school adolescent girls and their parents, Gondar City Administration, northwest Ethiopia, $2017(n=795)$

\begin{tabular}{|c|c|c|c|c|c|}
\hline & & & & & \\
\hline Variables & Frequency & Percent & Variables & Frequency & Percent \\
\hline Age & & & Daily laborer & 41 & 5.2 \\
\hline Early & 140 & 17.6 & Merchant & 85 & 10.7 \\
\hline Middle & 415 & 52.2 & Others & 41 & 5.2 \\
\hline Late & 240 & 30.2 & Family size & & \\
\hline Level of education & & & $<=5$ & 430 & 54.1 \\
\hline Primary & 301 & 37.6 & $>5$ & 365 & 45.9 \\
\hline High school & 428 & 53.8 & School enrolled & & \\
\hline Preparatory school & 66 & 8.3 & Government & 630 & 79.2 \\
\hline Religion & & & Private & 165 & 20.8 \\
\hline Orthodox & 760 & 95.6 & Wealth index & & \\
\hline Muslim & 28 & 3.5 & 1st quintile & 168 & 21.1 \\
\hline Others & 7 & 0.9 & 2nd quintile & 219 & 27.5 \\
\hline Place of residence & & & 3rd quintile & 208 & 26.2 \\
\hline Urban & 742 & 93.3 & 4th quintile & 200 & 25.2 \\
\hline
\end{tabular}

Ethnicity

$\begin{array}{ll}\text { Amhara } & 754 \\ \text { Oromo } & 12 \\ \text { Tigray } & 9 \\ \text { Others } & 20\end{array}$

Others

Marital status of girls

Not Married

married

82

Educational status of father

Informal education

Primary

Secondary

College and above

Occupation of father

Government employee

Farmer

Daily laborer

Merchant

NGOS

Educational status of mother

$\begin{array}{ll}\text { Informal education } & 43 \\ \text { Primary } & 12 \\ \text { Secondary } & 128 \\ \text { College and above } & 108 \\ \text { Occupation of mother } & \end{array}$

Government employee $\quad 129$

Housewife
Table 1 Socio-demographic characteristics of school adolescent girls and their parents, Gondar City Administration, northwest Ethiopia, 2017 ( $n=795)$ (Continued)

In fact, pregnancy demands significantly high energy and micronutrients even the requirement increases in case of adolescence pregnancy to support tremendous growth of both the adolescent and the fetus. Therefore, adolescence pregnancy amplifies the vulnerability of girls for under nutrition, including stunting [33]. In contrast, our finding is higher than the former local and abroad reports, such as Tigray Region, 26.5\% [34], Adwa Town 12.2\% [19], western Kenya 12.1\% [15] and Nigeria $17.9 \%$. This discrepancy could be related to socioeconomic disparities between the study settings.

The result of the adjusted analysis showed that girls in the early and middle adolescence were $74 \%$ and $78 \%$ times less likely to be stunted, respectively, as compared to late adolescent girls. Similar finding was reported in urban set up of Kathmandu valley [31]. This could be due to the fact that sudden increase in height after the first menstruation in the middle age group and in the later time. Therefore, enhancing energy and micronutrient intake has special importance in the late adolescence.

Adolescent girls whose mothers did not have formal education were 2.84 times more likely to be stunted as compared to those whose mothers completed college and above education. This finding is supported by the study done in Bangladesh [14] and Nigeria. This may due to the fact that low job access and poor household decision making power are common social problems of poorly educated mothers which could affect nutritional status of children, including adolescents. Furthermore, early marriage and poor utilization of family planning are also observed among women with low education [35]. 
Table 2 Nutritional and health related characteristics of school adolescent girls, Gondar City Administration, northwest Ethiopia, $2017(n=795)$

\begin{tabular}{|c|c|c|}
\hline Variables & Frequency & Percent \\
\hline \multicolumn{3}{|c|}{ Meal frequency per day } \\
\hline$<3$ & 87 & 10.9 \\
\hline$>=3$ & 708 & 89.1 \\
\hline \multicolumn{3}{|c|}{ Household food security } \\
\hline Secured & 499 & 62.8 \\
\hline In secured & 296 & 37.2 \\
\hline \multicolumn{3}{|c|}{ Dietary diversity score } \\
\hline Adequate & 600 & 75.5 \\
\hline Inadequate & 195 & 24.5 \\
\hline \multicolumn{3}{|c|}{ Two weeks history of illness } \\
\hline Yes & 160 & 20.1 \\
\hline No & 635 & 79.9 \\
\hline \multicolumn{3}{|c|}{ Member of association } \\
\hline Yes & 148 & 18.6 \\
\hline No & 647 & 81.4 \\
\hline \multicolumn{3}{|l|}{ Media exposure } \\
\hline Satisfactory & 631 & 79.4 \\
\hline Unsatisfactory & 164 & 20.6 \\
\hline \multicolumn{3}{|c|}{ Menstruation status } \\
\hline Yes & 599 & 71.3 \\
\hline No & 196 & 24.7 \\
\hline \multicolumn{3}{|c|}{ Age of first menarche } \\
\hline $10-13$ & 163 & 20.5 \\
\hline $14-16$ & 358 & 45 \\
\hline $17-19$ & 78 & 5.8 \\
\hline \multicolumn{3}{|c|}{ Past history of pregnancy } \\
\hline Yes & 35 & 4.4 \\
\hline No & 760 & 95.6 \\
\hline
\end{tabular}

The odds of stunting were 1.69 times higher among adolescent girls who had unsatisfactory media exposure compared to those who had satisfactory media exposure. The observed association could be explained by the positive effect of media in changing unhealthy eating behaviors of the community which in turn could contribute for better nutritional outcomes through delivering reliable and clear nutrition information [25]. Moreover, adolescent girls with adequate media exposure might indirectly show their good economic status which in turn indicates resource availability at the household level to improve purchase diversified diet. One the previous scientific report also affirmed that poor feeding practice was associated with adolescents limited media exposure which in turn affect their nutrition condition [36].
Table 3 Environmental characteristics of school adolescent girls in Gondar City Administration, Northwest Ethiopia, 2017

\begin{tabular}{|c|c|c|}
\hline Variables & Frequency & Percent \\
\hline \multicolumn{3}{|c|}{ Availability of home gardening } \\
\hline Yes & 131 & 16.5 \\
\hline No & 664 & 83.5 \\
\hline \multicolumn{3}{|c|}{ Purpose of home gardening } \\
\hline For home & 13 & 9.9 \\
\hline For sale & 69 & 52.7 \\
\hline For sale and home & 49 & 37.4 \\
\hline \multicolumn{3}{|c|}{ Source of drinking water } \\
\hline Improved & 783 & 98.5 \\
\hline Unimproved & 12 & 1.5 \\
\hline \multicolumn{3}{|l|}{ Wate water treatment } \\
\hline yes & 595 & 74.8 \\
\hline No & 200 & 25.2 \\
\hline \multicolumn{3}{|c|}{ Distance of water source } \\
\hline$<=30 \mathrm{~min}$ & 785 & 98.5 \\
\hline$>30$ & 12 & 1.5 \\
\hline \multicolumn{3}{|c|}{ Availability of home latrine } \\
\hline yes & 629 & 79.1 \\
\hline No & 166 & 20.9 \\
\hline \multicolumn{3}{|c|}{ Availability of waste disposal/garbage } \\
\hline Yes & 735 & 92.5 \\
\hline No & 60 & 7.5 \\
\hline \multicolumn{3}{|c|}{ Hand washing after toilet } \\
\hline Yes & 784 & 98.4 \\
\hline No & 11 & 1.4 \\
\hline \multicolumn{3}{|l|}{ Use of detergent/soap } \\
\hline Yes & 702 & 88.3 \\
\hline No & 93 & 11.2 \\
\hline
\end{tabular}

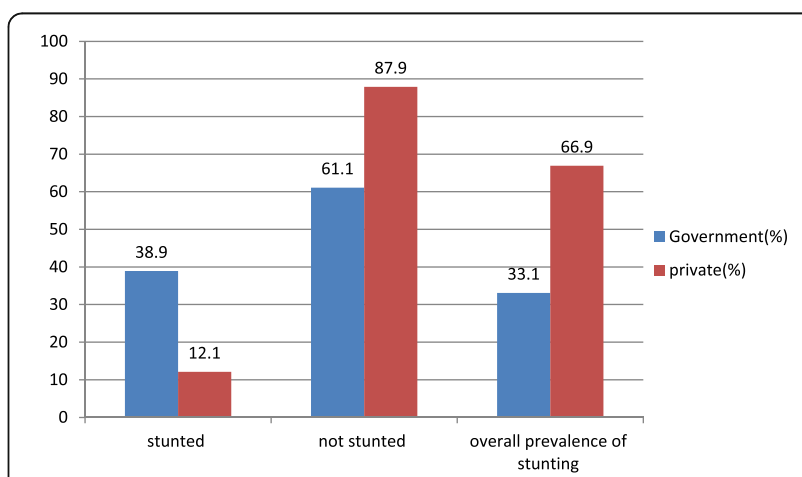

Fig. 1 Prevalence and distribution of stunting among adolescent girls stratified by school type, Gondar City Administration, northwest Ethiopia, 2017 
Table 4 Bivariate and multivariable logistic regression output showing that factors associatedwith stunting among school adolescent girls, Gondar City Administration, northwest Ethiopia, 2017

\begin{tabular}{|c|c|c|c|c|}
\hline \multirow[t]{2}{*}{ Variables } & \multicolumn{2}{|l|}{ Stunting } & \multirow{2}{*}{$\begin{array}{l}\text { Crude Odds } \\
\text { Ratio with } \\
95 \% \text { C) }\end{array}$} & \multirow{2}{*}{$\begin{array}{l}\text { Adjusted } \\
\text { Odds Ratio } \\
\text { with 95\% Cl }\end{array}$} \\
\hline & Stunted & Not stunted & & \\
\hline \multicolumn{5}{|l|}{ Age of adolescent } \\
\hline Early & $3(2.1 \%)$ & 137(97.9\%) & $0.01(0.00,0.04)$ & $0.26(0.00,0.22)^{\mathrm{a}}$ \\
\hline Middle & $112(27 . \%)$ & $303(73 \%)$ & $0.23(0.16,0.32)$ & $0.22(0.15,0.34)^{\mathrm{a}}$ \\
\hline Late & $148(61.7 \%)$ & $92(38.3 \%)$ & 1 & 1 \\
\hline \multicolumn{5}{|c|}{ Educational level of respondents } \\
\hline Primary & $48(16 \%)$ & 253(84\%) & $0.15(0.08,0.26)$ & $0.68(0.28,1.85)$ \\
\hline High school & $178(41.6 \%)$ & $250(58.4 \%)$ & $0.56(.33, .94)$ & $0.95(0.49,1.85)$ \\
\hline Preparatory school & $37(56.1 \%)$ & $29(43.9 \%)$ & 1 & 1 \\
\hline \multicolumn{5}{|l|}{ School enrolled } \\
\hline Government & $243(38.9 \%)$ & $382(61.1 \%)$ & $4.61(2.77,7.46)$ & $1.49(0.71,3.14)$ \\
\hline Private & $20(12.1 \%)$ & 145(87.9\%) & 1 & 1 \\
\hline \multicolumn{5}{|l|}{ Educational status of father } \\
\hline Informal education & $156(41.2 \%)$ & $223(58.8 \%)$ & $2.11(1.43,3.12)$ & $0.91(0.51,1.74)$ \\
\hline Primary & $29(29 \%)$ & $71(71 \%)$ & $1.23(0.71,2.13)$ & $0.71(0.32,1.54)$ \\
\hline Secondary & $32(24.4 \%)$ & $99(75.6 \%)$ & $0.97(.58,1.64)$ & $0.66(0.32,1.36)$ \\
\hline College and above & $46(24.9 \%)$ & 139(75.1\%) & 1 & 1 \\
\hline \multicolumn{5}{|c|}{ Educational status of mothers } \\
\hline Informal education & $178(40.7 \%)$ & $259(59.3 \%)$ & $2.85(1.70,4.76)$ & $2.84(1.02,7.94)^{\mathrm{a}}$ \\
\hline Primary & $29(23.8 \%)$ & $93(76.2 \%)$ & $1.29(0.69,2.43)$ & $2.01(0.69,5.81)$ \\
\hline Secondary & $35(27.3 \%)$ & $93(72.7 \%)$ & $1.59(0.48,2.88)$ & $2.26(0.85,6.03)$ \\
\hline College and above & $21(19.4 \%)$ & $87(80.6 \%)$ & 1 & 1 \\
\hline \multicolumn{5}{|l|}{ Occupation of the mothers } \\
\hline Government employee & $44(34.1 \%)$ & $85(65.9 \%)$ & $1.61(0.72,3.57)$ & $1.66(0.55,5.03)$ \\
\hline Housewife & $175(35.1 \%)$ & $324(64.9 \%)$ & $1.67(0.80,3.51)$ & $0.78(0.30,2.04)$ \\
\hline Daily laborer & 15(36.6\%) & $26(63.4 \%)$ & $1.79(0.69,4.65)$ & $0.63(0.18,2.22)$ \\
\hline Merchant & $19(22.4 \%)$ & $66(77.6 \%)$ & $0.89(0.37,2.14$ & $0.41(0.13,1.28)$ \\
\hline Others & $10(24.4 \%)$ & $31(75.6 \%)$ & 1 & 1 \\
\hline \multicolumn{5}{|l|}{ Dietary diversity } \\
\hline Adequate & $187(31.2 \%)$ & $413(68.8 \%)$ & 1 & 1 \\
\hline Inadequate & $76(39 \%)$ & $119(61 \%)$ & $1.41(1.00,1.97)$ & $1.06(0.70,1.61)$ \\
\hline \multicolumn{5}{|l|}{ Wealth index } \\
\hline 1st quintile & $77(45.8 \%)$ & $91(54.2 \%)$ & $2.23(1.44,3.44)$ & $1.72(0.95,3.12)$ \\
\hline 2nd quintile & 73(33.3\%) & $146(66.7 \%)$ & $1.31(0.86 .1 .57)$ & $1.01(0.61,1.86)$ \\
\hline 3rd quintile & $58(\%)$ & $150(\%)$ & $1.01(0.66,1.57)$ & $0.82(0.47,1.43)$ \\
\hline 4th quintile & $55(27.9 \%)$ & $145(72.1 \%)$ & 1 & 1 \\
\hline \multicolumn{5}{|l|}{ Availability of latrine } \\
\hline Yes & 192(30.5\%) & $437(69.5 \%)$ & 1 & 1 \\
\hline No & $71(42.8 \%)$ & $95(57.2 \%)$ & $1.70(1.19,2.41)$ & $0.74(0.38,1.45)$ \\
\hline \multicolumn{5}{|l|}{ Menstruation status } \\
\hline $10-13$ & $57(35 \%)$ & $106(65 \%)$ & $0.40(0.09 .1 .87)$ & $0.86(0.54,1.37)$ \\
\hline $14-16$ & $152(42.5 \%)$ & $206(57.5 \%)$ & $0.55(0.12,2.51)$ & $0.99(0.17,5.61)$ \\
\hline 17-19 & $4(57.1 \%)$ & $3(42.9 \%)$ & 1 & 1 \\
\hline
\end{tabular}


Table 4 Bivariate and multivariable logistic regression output showing that factors associatedwith stunting among school adolescent girls, Gondar City Administration, northwest Ethiopia, 2017 (Continued)

\begin{tabular}{|c|c|c|c|c|}
\hline \multirow[t]{2}{*}{ Variables } & \multicolumn{2}{|l|}{ Stunting } & \multirow{2}{*}{$\begin{array}{l}\text { Crude Odds } \\
\text { Ratio with } \\
95 \% \text { C) }\end{array}$} & \multirow{2}{*}{$\begin{array}{l}\text { Adjusted } \\
\text { Odds Ratio } \\
\text { with } 95 \% \mathrm{Cl}\end{array}$} \\
\hline & Stunted & Not stunted & & \\
\hline \multicolumn{5}{|l|}{ Media exposure } \\
\hline Satisfactory & $225(35.7 \%)$ & $406(64.3 \%)$ & 1 & 1 \\
\hline Unsatisfactory & $38(23.2 \%)$ & $126(76.8 \%)$ & $0.54(0.36,0.81)$ & $1.69(1.01,2.84)^{\mathrm{a}}$ \\
\hline \multicolumn{5}{|c|}{ Past history of pregnancy } \\
\hline No & $222(39.3 \%)$ & $343(60.7 \%)$ & 1 & 1 \\
\hline Yes & $19(54.3 \%)$ & $16(45.7 \%)$ & $1.84(0.92,3.64)$ & $0.46(0.21,0.98)$ \\
\hline \multicolumn{5}{|c|}{ Past two weeks history of illness } \\
\hline No & $222(39.3 \%)$ & $343(60.7 \%)$ & 1 & 1 \\
\hline Yes & 19(3.7\%) & $501(96.3 \%)$ & $0.72(0.49,1.06)$ & $0.51(0.23,1.50)$ \\
\hline \multicolumn{5}{|c|}{ Household food security } \\
\hline Secured & $174(34.9 \%)$ & $325(65.1 \%)$ & 1 & 1 \\
\hline In secured & 89(30.1\%) & $207(69.9 \%)$ & $1.25(0.91,1.71)$ & $0.81(0.52,1.26)$ \\
\hline \multicolumn{5}{|c|}{ Availability of waste disposal/garbage } \\
\hline No & $29(48.3 \%)$ & $31(51.7 \%)$ & $2.00(1.18,3.40)$ & $0.73(.371,1.43)$ \\
\hline Yes & $234(31.8 \%)$ & $501(68.2 \%)$ & 1 & 1 \\
\hline \multicolumn{5}{|c|}{ Availability of home gardening } \\
\hline No & 213(32.1\%) & $451(67.9 \%)$ & $0.77(0.52,1.13)$ & $0.69(0.42,1.12)$ \\
\hline Yes & $50(38.2 \%)$ & $81(61.8 \%)$ & 1 & 1 \\
\hline
\end{tabular}

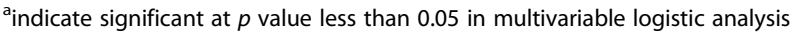

Though this study tried fill the knowledge gap by showing the burden and related characteristics of adolescent stunting, some of the limitations should be taken into consideration. Firstly, water and sanitary services of the school environment is not assessed. Secondly, recall bias in measuring the dietary diversity and household food security status are also the possible limitation of the study, although different efforts, as described in the method section, were made to minimize it.

\section{Conclusion}

In summary, one-third of adolescent girls are stunted in Gondar District which confirmed serious public health importance of the problem. Age and media exposure of adolescents and mothers education were significantly associated with stunting. Therefore enhancing mother's education and access to media are important to address the high burden of stunting.

\section{Abbreviations}

AOR: Adjusted odds ratio; BSC: Bachelors of science; Cl: Confidence interval; CM: Centimeter; COR: Crud odds ratio; DDS: Dietary diversity score;

EDHS: Ethiopian demographic and health survey; FAO: Food and Agriculture Organization; HAZ: Height -for-age; HFS: Household food security;
MSC: Masters of science; PCA: Principal component analysis; SPSS: Statistical package for social sciences; SRS: Systematic random sampling; WHO: World Health Organization

\section{Acknowledgements}

The authors would like to thank all respondents for their willingness to participate in the study. They are also grateful to all school principals, teachers, and parents for their cooperation. Authors would like to thank University of Gondar for material support.

\section{Ethical consideration and consent to participate}

Ethical clearance was obtained from the Institutional Review Board of the University of Gondar. Official letters of co-operation submitted to all primary, secondary schools and city administration education office. Students and their parents were notified and necessary explanations were also given about the purposes, procedure and ethical issues of the study. Consent was collected from the parents of study subjects by sending letter to parent/guardians for each study subject less than 18 years old and oral assent was also obtained from study subjects in the school. The purpose of the study was explained and written informed consent was secured. Confidentiality was maintained at all levels of the study. Participant's involvement in the study was on voluntary basis; participants who were not volunteer to participate in the study and those who wish to quit their participation at any stage were informed to do so without any restriction. The respondents' confidentiality of information was assured by excluding names and identifiers from in the questionnaire.

Funding

No fund was obtained for this study.

Availability of data and materials

Data will be available upon request from the corresponding authors. 


\section{Authors' contributions}

SM conceived the study, developed the tool, coordinated the data collection activity, and carried out the statistical analysis. AK participated in the design of the study, tool development, and drafting the manuscript. AT participated in the design of the study and tool development, performed statistical analysis, and reviewed the manuscript. All authors read and approved the final manuscript.

\section{Consent for publication}

Not applicable.

\section{Competing interests}

The authors declare that they have no competing interest.

\section{Publisher's Note}

Springer Nature remains neutral with regard to jurisdictional claims in published maps and institutional affiliations.

\section{Author details}

'Gondar University Teaching and Referral Hospital, University of Gondar, Gondar, Ethiopia. ${ }^{2}$ Department of Human Nutrition, Institute of Public Health, University of Gondar, Gondar, Ethiopia.

\section{Received: 28 July 2017 Accepted: 29 January 2018} Published online: 07 March 2018

\section{References}

1. Unicef. UNICEF data: monitoring the situation of children and women. The state of the World's children report. 2015.

2. Prentice AM, Jarjou LM, Moore SE, Fulford AJ, Ward K, Goldberg GR, et al. Critical windows for nutritional interventions against stunting reply. Am J Clin Nutr. 2013;98(3):856-7.

3. WHO. Global nutrition targets 2025: stunting policy brief. 2014.

4. Fleming A, Briggs N, Rossiter C. 5. Growth during pregnancy in Nigerian teenage primigravidae. BJOG Int J Obstet Gynaecol. 1985;92(s5):32-9.

5. Brabin L, Brabin BJ. The cost of successful adolescent growth and development in girls in relation to iron and vitamin a status. Am J Clin Nutr. 1992;55(5):955-8.

6. McGuire $\mathrm{S}$, World Health Organization. Comprehensive implementation plan on maternal, infant, and young child nutrition. Geneva, Switzerland, 2014. Adv Nut Int Rev J. 2015;6(1):134-5.

7. Akseer $\mathrm{N}$, et al. Global and regional trends in the nutritional status of young people: a critical and neglected age group. Ann N Y Acad Sci. 2017;1393(1):3-20

8. Bhutta ZA, Das JK, Rizvi A, Gaffey MF, Walker N, Horton S, et al. Evidencebased interventions for improvement of maternal and child nutrition: what can be done and at what cost? Lancet. 2013;382(9890):452-77.

9. World Health organization. WHA global nutrition targets 2025: stunting policy brief. 2013.

10. Save the Children. Adolescent nutrition policy and programming in SUN+ countries. 2015

11. Medhi G, Hazarika N, Mahanta J. Nutritional status of adolescents among tea garden workers. Indian J Pediatr. 2007;74(4):343-7.

12. Prashant K, Shaw C. Nutritional status of adolescent girls from an urban slum area in South India. Indian J Pediatr. 2009:76(5):501-4.

13. Aguayo VM, Paintal K. Nutrition in adolescent girls in South Asia. BMJ. 2017; 357:j1309.

14. Rah JH, Christian P, Shamim AA, Arju UT, Labrique AB, Rashid M. Predictors of stunting and thinness in post-menarcheal adolescent girls in rural Bangladesh. Public Health Nutr. 2009;12(12):2400-9.

15. Leenstra T, Petersen L, Kariuki S, Oloo A, Kager P, Ter Kuile F. Prevalence and severity of malnutrition and age at menarche; cross-sectional studies in adolescent schoolgirls in western Kenya. Eur J Clin Nutr. 2005;59(1):41-8.

16. Senbanjo IO, Oshikoya KA, Odusanya OO, Njokanma OF. Prevalence of and risk factors for stunting among school children and adolescents in Abeokuta, Southwest Nigeria. J Health Popul Nutr. 2011:29(4):364.

17. GotFDR E. National Nutrition Programme June 2013-June 2015. Addis Ababa: Government of Federal Democratic Republic of Ethiopia; 2013.

18. Roba K, Abdo M, Wakayo T. Nutritional status and its associated factors among school adolescent girls in Adama City, Central Ethiopia. J Nutr Food Sci. 2016;6(493):2.
19. Gebregyorgis T, Tadesse T, Atenafu A. Prevalence of thinness and stunting and associated factors among adolescent school girls in Adwa Town, North Ethiopia. Int J Food Sci. 2016;2016:P.8323982.

20. Weres Z, Yebyo H, Miruts K, Gesesew H, Woldehymanot T. Assessment of Adolescents' under nutrition level among school students in eastern Tigray, Ethiopia: a cross-sectional study. J Nutr Food Sci. 2015;5(5):1.

21. Melaku YA, Zello GA, Gill TK, Adams RJ, Shi Z. Prevalence and factors associated with stunting and thinness among adolescent students in northern Ethiopia: a comparison to World Health Organization standards. Arch Public Health. 2015;73(1):44

22. Delisle HIn, WHO. Nutrition in adolescence: issues and challenges for the health sector: issues in adolescent health and development. 2005.

23. Hall A, Kassa $T$, Demissie $T$, Degefie $T$, Lee $S$. National survey of the health and nutrition of schoolchildren in Ethiopia. Tropical Medicine \& International Health. 2008;13(12):1518-26.

24. Ethiopian Health and Nutrition Research Institute. Nutrtion baseline survey report for the National Nutrition Program of Ethiopia. 2009.

25. Wassie MM, Gete AA, Yesuf ME, Alene GD, Belay A, Moges T. Predictors of nutritional status of Ethiopian adolescent girls: a community based cross sectional study. BMC Nutr. 2015;1(1):20.

26. Ethiopian Public Health Institute. Ethiopian national nutrition program endline survey. 2015.

27. Ethiopia CS. Summary and statistical report of the 2007 population and housing census. Addis Ababa, Ethiopia: Federal democratic republic of Ethiopia population census commission. 2008:1-0

28. WHO. Growth reference data for 5-19 years. Geneva: WHO; 2007.

29. Kennedy G, Razes M, Ballard T, Dop MC, editors. Measurement of dietary diversity for monitoring the impact of food based approaches. International symposium on food and nutrition security: food-based approaches for improving diets and raising levels of nutrition; 2010.

30. Bickel G, Nord M, Price C, Hamilton W, Cook J. Guide to measuring household food security. Revised; 2000

31. Shrestha B. Anthropometrically determined Undernutrition among the adolescent girls in Kathmandu Valley. Kathmandu Univ Med J. 2017;13(3):224-9.

32. Black R, Hopkins BJ. The lancet series on maternal and child Undernutrition, executive summary. Lancet. 2008;371:1-10.

33. Lenders CM, McElrath TF, Scholl TO. Nutrition in adolescent pregnancy. Curr Opin Pediatr. 2000;12(3):291-6.

34. Mulugeta A, Hagos F, Kruseman G, Linderhof V, Stoecker B, Abraha Z, et al. Child malnutrition in Tigray, northern Ethiopia. East Afr Med J. 2010;87(6): 248-54.

35. World Health Organization. Global nutrtion report from promise to impact ending malnutrition by 2030. 2016

36. Hoddinott J, Naureen I, Karachiwalla NA, Ledlie RS. Adolescent girls' infant and young child nutrition knowledge levels and sources differ among rural and urban samples in Bangladesh. Matern Child Nutr. 2016:12:885-97.

\section{Submit your next manuscript to BioMed Central and we will help you at every step:}

- We accept pre-submission inquiries

- Our selector tool helps you to find the most relevant journal

- We provide round the clock customer support

- Convenient online submission

- Thorough peer review

- Inclusion in PubMed and all major indexing services

- Maximum visibility for your research

Submit your manuscript at www.biomedcentral.com/submit
Biomed Central 